\title{
LITERATURA INFANTIL: UM ENCONTRO COM A INFÂNCIA DO MUNDO
}

\section{CHILDREN'S LITERATURE: AN ENCOUNTER WITH THE WORLD'S CHILDHOOD}

\author{
LITERATURA INFANTIL: UN ENCUENTRO CON LA NIÑEZ DEL MUNDO
}

\author{
Juliana Bruna Freitas ${ }^{1}$
}

\begin{abstract}
Resumo: As publicações contemporâneas em Literatura Infantil indicam que o gênero promoveu um deslocamento das intenções que marcaram a sua origem, estreitando, dessa maneira, o seu compromisso com a arte e o seu público final - a criança. Diante desse cenário, a presente pesquisa investiga o potencial da literatura infantil em contrapor as maneiras já conhecidas, como a ciência, de se relacionar, pensar e produzir conteúdos sobre a infância. Partiu-se da hipótese de que a Literatura Infantil, desobrigada da intenção de controlar e sistematizar a infância, oferece uma riqueza de descrições sobre a criança, as quais deslocam o olhar adultocêntrico na medida em que valorizam e buscam o olhar infantil para as produções. Em termos metodológicos foi utilizado uma metodologia bibliográfica de caráter exploratório. Dentre as conclusões, chama-se atenção para o potencial da arte, em especial a Literatura Infantil, em contrapor à fragmentação e cristalização da infância. Além disso, a pesquisa também indica a necessidade de que a experimentação do livro infantil transcenda o olhar estritamente pedagógico e utilitarista.

Palavras-chave: Literatura infantil; arte; infância.
\end{abstract}

\begin{abstract}
Contemporary publications in Children's Literature indicate that gender promoted a shift from intentions that marked its origin, strengthening, in this way, his commitment to art and his final audience - the child. In view of this scenario, this research investigates the potential of children's literature in countering the ways already known of relating, thinking and producing content about childhood. It was based on the hypothesis that Children's Literature, released from the intention to control and systematize childhood, offers a wealth of descriptions about the child, which displace the adult-centered gaze. In methodological terms, an exploratory bibliographic methodology was used. Among the conclusions, attention is drawn to the potential of Children's Literature in countering the fragmentation and crystallization of childhood. In addition, the research also indicates the need for the experimentation of the children's book to transcend the strictly pedagogical and utilitarian look.
\end{abstract}

Keywords: Children's literature; art; childhood.

Resumen: Las publicaciones contemporáneas de Literatura Infantil indican que el género ha promovido un alejamiento de las intenciones que marcaron su origen, estrechando su compromiso con el arte y su público final: el niño. Ante este escenario, la presente investigación indaga en el potencial de la literatura infantil para contraponer las formas ya conocidas, como la ciencia, de relacionarse, pensar y producir contenidos sobre la infancia. Se partió de la base de que la Literatura Infantil, libre de la intención de controlar y sistematizar la infancia, ofrece descripciones sobre el niño, que desplazan la mirada centrada en el adulto en la medida en que valoran y buscan la mirada del niño para las producciones. Desde el punto de vista metodológico, se utilizó una metodología bibliográfica de carácter exploratorio. Entre las conclusiones, se destaca el potencial de la literatura infantil para contrarrestar la fragmentación

\footnotetext{
${ }^{1}$ Pontifícia Universidade Católica de Minas Gerais.
} 
y cristalización de la infancia. Además, la investigación también indica la necesidad de que la experimentación del libro infantil trascienda la mirada estrictamente pedagógica y utilitaria.

Palabras clave: Literatura infantil; arte; infancia.

\section{Introdução}

Com forte influência da pedagogia, a literatura infantil por muito tempo veiculou conteúdos moralizantes no intuito de doutrinar o público infantil. Em vista disso, o gênero ganhou ares pragmáticos e uma única finalidade: educar e incutir valores morais na criança. $\mathrm{O}$ prazer e a sedução do texto ficavam para os adultos. Zilberman (2003) comenta que ainda hoje a Literatura Infantil permanece como uma colônia da pedagogia, o que lhe causa grandes prejuízos: não é aceita como arte, por ter uma finalidade pragmática, e a presença do didático faz com que ela participe de uma atividade comprometida com a dominação da criança.

Para tanto, a imagem predominante era a criança angelical, pura e inocente. Nesse sentido, os personagens representavam esse ideal de eu, tão valorizado pelo universo adulto. No entanto, com as mudanças sociais, econômicas e culturais, a criança 'real' foi ganhando espaço no texto a ela destinado. Desse modo, embora com uma forte tradição pedagógica ainda presente no gênero, é possível encontrar textos infantis nos quais há um maior compromisso com a arte, afinal, "a arte tem outros desígnios e desejos, a criança também" (PALO; OLIVEIRA, 1998, p. 7).

Portanto, é certo afirmar que as publicações contemporâneas da literatura infantil reforçam o compromisso com a arte em detrimento do viés doutrinário, o que sugere uma maior liberdade de criação e preocupação com a forma e conteúdo, colocando, dessa maneira, as obras para criança em um mesmo patamar de crítica do que a literatura como um todo.

Diante desse cenário, que reafirma o caráter estético da literatura infantil, a presente pesquisa investiga o potencial desse gênero em representar e contrapor uma maneira de se relacionar, pensar e produzir conteúdo sobre a infância. Partiu-se da hipótese de que a Literatura Infantil, desobrigada da intenção de controlar e sistematizar a infância, oferece uma riqueza de descrições sobre a criança, as quais deslocam o olhar adultocêntrico na medida em que valorizam e buscam o olhar infantil para as produções.

\section{Justificativa}

O problema de pesquisa nasceu a partir de duas observações. A primeira de que a Literatura Infantil, embora tenha reafirmado o compromisso com a arte, ainda parece ser experimentada, no geral, com fins utilitários e pedagógicos. Em outras palavras, apesar de o gênero ter passado por grandes transformações, a sua representação social e consumo ainda está vinculado às intenções de doutrinação e moralização do público infantil. Diante disso, se faz necessário apontar para outras maneiras de experienciar a literatura infantil.

A segunda observação se refere à maneira como a sociedade se relaciona e pensa a infância. No livro História social da infância no Brasil, ao se dedicar ao estudo das fontes que compõem uma história da infância, o pesquisador Marcos Cezar Freitas (2016) aponta que certas fontes, como práticas discursivas da medicina, pedagogia e psicologia, "operam com imagens sobre a infância que [...] revelam em muitos casos uma 'fantasmagórica' autonomia em relação ao ser social representado na imagem outorgada pelo argumento científico...". Ao tratar da história social da criança, Freitas (2016) também reflete sobre a existência de imagens socialmente cristalizadas da infância, além de um estrangeirismo do objeto de estudo.

Tendo em vista esse cenário, que indica que as imagens da infância são, em alguns casos, estranhas às próprias crianças, se torna indispensável refletir sobre a maneira como a sociedade 
conhece e se relaciona com a infância, em um exercício de questionar a mentalidade contemporânea. Também se torna útil explorar outras fontes e maneiras de se aproximar e refletir sobre a infância, além daquelas marcadas pela autoridade científica. É nesse contexto que se localiza o tema da presente pesquisa - a Literatura Infantil, a qual também representa uma outra fonte de acesso à infância do mundo. Fonte esta que não tem compromisso em controlar, sistematizar ou legitimar uma verdade sobre a experiência da infância.

\section{Considerações metodológicas}

Tendo em vista a particularidade da pesquisa com textos literários, a pesquisa bibliográfica foi escolhida para balizar o processo investigativo. Em sintonia com a caracterização de pesquisa bibliográfica apresentada por Gil (2008), esta pesquisa foi elaborada com base em material já publicado, como livros acadêmicos, artigos científicos e livros infantis. Como a investigação explora um novo ângulo de uma relação já conhecida, é possível caracterizá-la, de certa forma, como um estudo exploratório, não pela natureza, mas pela perspectiva adotada.

No que se refere ao critério de escolha dos livros infantis que compõem as fontes da pesquisa, optou-se por autores e ilustradores que foram laureados recentemente com chancelas relevantes no universo da Literatura Infantil, como o prêmio Jabuti e o selo Altamente Recomendável da Fundação Nacional do Livro Infantil e Juvenil - FNLIJ.

De início, o caminho argumentativo perpassa a história da literatura infantil, acentuando os seus marcos e rupturas. Em sequência é analisado o processo de leitura, indicando as possíveis maneiras de se relacionar com o texto, assunto elementar dado o histórico utilitarista de consumo e veiculação da literatura infantil. Em seguida, é a vez dos livros infantis serem objeto de análise, para tanto a pesquisa se apoiou nos escritos do filósofo francês Paul Ricoeur. Após esse momento, a pesquisa se dedica a intencionalidade e função da literatura infantil. Por fim, o texto é concluído sugerindo uma atitude ética - a poética da infância, para nomear o modo de ser criança no mundo que encontra correspondência nas produções literárias.

\section{Literatura infantil: origens e desafios}

Em meados do século XVII um novo modo de se produzir Literatura ganhou os seus primeiros contornos. Nesse momento, nomes como Charles Perrault, Christian Andersen, Collodi, Lewis Carrol e Frank Baum chamam a atenção. A emergência do gênero está atrelada a alguns marcos de ordem social e econômica, como a ascensão da família burguesa e o novo status concedido à infância na sociedade. Além disso, outra vinculação que legitimou e subsidiou o aparecimento e expansão da Literatura Infantil foi a sua associação com a pedagogia.

A associação pedagógico-utilitária delineou, em grande parte, os modos de produção em Literatura Infantil, na medida em que delimitou um fim pedagógico a esse gênero. Essa característica, como aponta Ziberman, contribuiu para a desvalorização dessa produção enquanto uma forma de manifestação artística. Nessa perspectiva, como aponta Palo e Oliveira (1998), o literário se reduziu a um simples meio para atingir uma finalidade educativa, a qual é externa ao texto propriamente dito.

Somado a essas críticas, a Literatura Infantil também é alvo de alguns preconceitos, na medida em que é caracterizada como simples, efêmera, acessível e destinada a um público pouco experiente. Público este que é também subestimado em suas capacidades de compreensão e contato com a arte. E é justamente o direcionamento a este público, o qual confere o adjetivo infantil ao gênero, que determina as especificidades da Literatura Infantil em comparação aos outros modos de se fazer literatura. 
No entanto, embora a trajetória da Literatura Infantil esteja marcada por uma tradição fortemente pedagógica e utilitária, pesquisas apontam para outra direção. Lígia Cademartori (1986), por exemplo, discorre que “a inegável natureza literária do texto para crianças já o coloca além dos objetivos pedagógicos comprometidos com a legitimação das instituições, costumes e crenças que a geração adulta quer legar à infantil"' (CADEMARTORI, 1986, p. 18).

E para que a Literatura Infantil usufrua de um valor estético literário é necessário o abandono do ponto de vista adulto, ampliação do horizonte temático de representação e incorporação de uma linguagem renovadora, atenta ao discurso da vanguarda, às modalidades da paródia, enfim, acompanhando a evolução da arte literária, que se dá sempre como ruptura e não como obediência. (ZILBERMAN, 2003, p. 69).

Zilberman aponta que somente quando a finalidade é o exercício com a palavra é que o texto para crianças atinge seu sentido autêntico, genuíno, o qual, para Kurt Werner se refere "à expansão da dimensão de entendimento da criança" (Zilberman, 2003). Corroborando essa ideia, Nelly Novaes Coelho, reconhecida escritora e crítica literária, discorre que "a literatura infantil é, antes de tudo, literatura; ou melhor, é arte: fenômeno de criatividade que representa o mundo, o homem, a vida, através da palavra. Funde os sonhos e a vida prática, o imaginário e o real, os ideais e sua possível/impossível realização" (COELHO, 2000, p. 27).

O campo literário é um espaço de experimentação, de liberdade de sonhar e inventar mundos até onde as variações imaginativas do autor nos puderem levar. Essa característica não difere para as produções em Literatura Infantil. Nota-se que assim como na Literatura no geral, há também na produção infantil obras em que o valor artístico é discutível, na medida em que apresentam finalidades pragmáticas que visam a moralização e dominação do público infantil. Segundo Bettelheim (1986) uma parcela da literatura denominada infantil é tão superficial em substância que pouco significado pode-se obter delas.

No entanto, embora produções com essa finalidade sejam recorrentes, generalizar esse julgamento para todas as obras é perder de vista o potencial desse gênero literário enquanto produtor de experiências estéticas. Nessa perspectiva, entende-se que a Literatura Infantil transcende a função de entretenimento para se aproximar de uma dimensão artística. Antes de adentrar em uma análise sobre os livros propriamente ditos, a presente pesquisa propõe a seguir uma breve reflexão sobre a recepção dos textos infantis.

\section{Os sentidos da leitura}

A palavra leitura assume diferentes interpretações a depender do tempo e espaço em que é evocada. Nas palavras de Hillesheim et al. (2011, p. 307) “o significado da palavra leitura é deslizante, uma vez que não remete imediatamente a um conceito, mas sim a um conjunto de práticas sociais sobre o ato de ler".

De acordo com a etimologia da palavra, a leitura pode representar um contar e enumerar letras, um colher de significados e por fim, uma forma de roubo. O processo de contar ou enumerar letras representa a etapa inicial da leitura. Já a leitura enquanto uma forma de colher algo está relacionada à tradicional interpretação de texto, fundamental em alguns contextos, mas não necessária em todos os processos de leitura (WALTY, 1995).

Por fim, a leitura enquanto um roubo carrega em si a ideia de subversão e clandestinidade, na medida em que o leitor tem o poder de fazer escolhas para além e, até contrárias, às palavras do escritor. Nessa dimensão, o leitor não é mais um efeito do livro, mas um elemento independente e poderoso (WALTY, 1995).

Na relação tradicional entre leitor adulto e Literatura Infantil, é possível que a dimensão mais explorada seja o colher, haja vista os manuais para psicólogos de como usar livros infantis 
no contexto clínico, os quais já indicam leituras possíveis, bem como o contexto e demanda ideal de trabalho. Embora essa dimensão tenha impactos positivos, ela não deve substituir outras formas de se relacionar com o texto infantil. Caso isso aconteça, o leitor fica refém de leituras já realizadas, bem como perde de vista o potencial da Literatura Infantil como um todo.

No livro Seis passeios pelos bosques da ficção (2019), Umberto Eco também apresenta diferentes formas de se relacionar com os textos ficcionais. Para o autor, assim como em um bosque, há duas formas de explorar um texto narrativo. A primeira é aquela que experimenta vários caminhos a fim de encontrar o seu destino final, que pode ser a casa da avó, do Pequeno Polegar ou de João e Maria. A outra forma de navegar nesse bosque é andar para ver como ele é e descobrir por que algumas trilhas são acessíveis e outras não.

Além dessas perspectivas, existem diversas outras formas de se compreender o ato da leitura. Algumas definições focam no texto, outras no leitor, outras dão ênfase ao encontro entre leitor e texto para explicar esse fenômeno. Independente do ponto de vista, é certo que a leitura representa um fenômeno complexo e polissêmico. Sem pretender esgotar o tema, o tópico a seguir apresenta algumas possíveis leituras de livros infantis.

\section{O livro infantil: leituras possíveis}

Assim como o ato da leitura envolve várias dimensões, a própria obra literária comporta uma diversidade de perspectivas. Para Paul Ricoeur (2010) um texto comporta três dimensões: a referencialidade, a comunicabilidade e a compreensão de si. Nas palavras do escritor

Um texto é uma mediação entre o ser humano e o mundo, entre o ser humano e o ser humano, entre o ser humano e ele mesmo; mediação entre ser humano e mundo é o que se chama de referencialidade; mediação entre o ser humano e o ser humano é a comunicabilidade; mediação entre o ser humano e ele mesmo é a compreensão de si. (RICOEUR, 2010, p. 204).

Nessa perspectiva, ler um texto nunca é só conhecer esta ou aquela história, mas é também se relacionar consigo, com outro e com o mundo. No caso do livro infantil, é possível conectar a referencialidade do texto à compreensão das diversas possibilidades de ser infância no mundo.

É o caso do projeto 'Um dia na Aldeia', desenvolvido em parceria com a editora Cosac Naify. Esta coleção apresenta seis livros infantis ${ }^{2}$ que tratam do cotidiano nas aldeias. A partir do projeto, os leitores conhecem o cotidiano das aldeias Ashaninka, Mbyá-Guarani, Wajãpi, Kisêdjê, Ikpeng e Panará. Todos os livros dessa coleção foram desenvolvidos a partir de filmes produzidos por cineastas indígenas com a colaboração dos índios moradores das aldeias.

Ainda no contexto indígena, outra obra infantil chama atenção: “A boca da noite". Escrito por Cristino Wapichana (2016), autor indígena do povo Wapichana, o livro conta a história de dois irmãos, Dum e Kupai. Curioso e inventivo, o menino Kupai quando ouve a expressão 'Boca da noite' não sossega até entendê-la. A partir da curiosidade do pequeno, a obra convida o leitor a conhecer a família, os costumes e a inventividade do povo indígena.

Além de aproximar os leitores dos diversos contextos nos quais as infâncias podem ser vivenciadas, livros infantis, assim como os contos de fadas, também apresentam diversos conflitos existenciais. É o caso do título "Pinóquio: o livro das pequenas verdades". No livro, Alexandre Rampazzo (2019) recupera o clássico personagem de Collodi dando outro foco a história que não a mentira, tão explorada em readaptações da narrativa.

\footnotetext{
${ }^{2}$ Livros que compõem a coleção: A história do monstro khátpy; No tempo do verão; Palermo e Neneco; Depois do ovo, a guerra; A história de Akykysia; Das crianças Ikpeng para o mundo.
} 
Na obra de Rampazzo, a margem que divide as duas páginas (direita e esquerda) também é a margem que separa o 'real' e o espelho no qual a cada virar de página Pinóquio se imagina sendo um personagem diferente. Nessa brincadeira entre sons, imagens e projeto gráfico o autor explora a questão da identidade, do ser quem se é, ser quem se sonha ser e do ser que se é esperado ser.

$\mathrm{Na}$ mesma linha, de narrativas que apresentam questões existenciais, é possível citar o livro "Olavo", do autor e ilustrador Odilon Moraes (2018). A primeira frase desta obra - "Olavo era um menino triste" - convida o leitor a conhecer essa personagem triste que recebe uma encomenda, mas escolhe não a abrir, afinal e se ela for endereçada a outra pessoa? Diante disso, o personagem prefere viver a alegria inofensiva de apenas tê-la recebido. Com delicadeza e poesia, o autor explora os conceitos de tristeza e alegria, provocando o leitor a pensar o tênue limite entre essas emoções.

Esses são alguns poucos exemplos da diversidade de narrativas que compõem o universo da Literatura Infantil. Embora o foco tenha sido a dimensão da referencialidade, em cada uma das obras apresentadas é possível identificar as três dimensões descritas por Paul Ricoeur.

No que se refere a dimensão da comunicabilidade de um texto, que diz de uma comunicação entre ser humano e ser humano, é possível ir por vários caminhos. Uma possibilidade, é a comunicação estabelecida por profissionais que trabalham com a infância. Segundo Mario Vargas Llosa "os conhecimentos que nos transmitem os manuais científicos e os tratados técnicos são fundamentais, mas eles não nos ensinam a dominar as palavras nem a exprimi-las com propriedade" (LLOSA, 2009, p. 23). Por isso, textos que pretendem se comunicar diretamente com as crianças são muito valiosos.

Segundo Palo e Oliveira,

Assumir um ponto de vista mais ou menos próximo do objeto da narração determinará, necessariamente, diferentes modos de vê-lo, cifrá-lo e significálo. No caso da literatura infantil, o foco narrativo participa de duas naturezas - a verbal e a visual - ambas tentando uma comunicação, a mais próxima e direta possível com a criança, recuperando a tradição da oralidade do 'Era uma vez' dos contos de fadas (PALO; OLIVEIRA, 1998, p. 43).

Diante disso, o livro infantil pode representar para o adulto um modelo a partir do qual é possível vislumbrar formas de se comunicar com os pequenos. Haja vista o predomínio nos livros infantis da oralidade sobre a linguagem escrita, mediante estruturas sintáticas próprias à expressão oral (ZILBERMAN, 2003).

Para elucidar essa relação é importante não perder de vista o processo de criação do livro infantil, no qual escritores e ilustradores partilham da intenção de serem compreendidos pelo seu público-alvo, as crianças. Sobre isso, Maria Lypp discorre que

A particularidade mais geral e fundamental deste processo de comunicação é a desigualdade entre os comunicadores, estando de um lado o autor adulto e, de outro, o leitor infantil. Ela diz respeito à situação linguística, cognitiva, ao status social, para mencionar os pressupostos mais importantes da desigualdade. $\mathrm{O}$ emissor deve desejar conscientemente a demolição da distância preexistente para avançar na direção do recebedor. Todos os meios empregados pelo autor para estabelecer uma comunicação com o leitor infantil podem ser resumidos sob a denominação de adaptação. (LYPP apud ZILBERMAN, 2003, p. 140).

Como já mencionado, na leitura de livros infantis, o leitor também não está isento de refletir sobre si mesmo, dimensão do texto denominada por Ricoeur de compreensão de si. Segundo Marcel Proust, "Todo leitor é, quando lê, o leitor de si mesmo. A obra não passa de 
uma espécie de instrumento óptico oferecido ao leitor a fim de lhe ser possível discernir o que, sem ela, não teria certamente visto em si mesmo" (PROUST, 2013, p. 256).

Nessa perspectiva, além de apresentar ao leitor as inúmeras possibilidades do ser criança no mundo, a Literatura Infantil também pode representar para o leitor adulto um espaço de encontro/ descoberta de si. O conteúdo e a forma das obras infantis podem suscitar no leitor lembranças da sua infância ou, ainda, apresentar elementos a partir dos quais o adulto signifique suas experiências.

Tendo em vista as leituras apresentadas é possível concluir que a Literatura Infantil representa um campo tão vasto quanto o seu próprio público. A seguir segue uma discussão sobre a função e o lugar da literatura infantil.

\section{As fronteiras da arte}

Entendida como toda criação de toque poético, dramático ou ficcional, a literatura é uma manifestação universal de todos os homens em todos os tempos (CANDIDO, 2012). Essa manifestação, diferente da ciência, trabalha com ambiguidades de sentidos e significados. De acordo com Coli (1995), enquanto a ciência necessita da ordem, da clarificação e da transparência, a arte, que extrai elementos do mundo sensível, produz um outro mundo capaz de atingir e enriquecer nossa sensibilidade. Segundo Coli

A arte não isola, um a um, os elementos da causalidade, ela não explica, mas tem o poder de nos "fazer sentir". Isso, evidentemente, não quer dizer que a arte substitui a causalidade científica, nem que ela se encontra em oposição à ciência. Nem explica, de outro modo, nem anula a explicação científica (COLI, 1995, p. 110).

Por essa razão, como afirma Dante Moreira Leite (2002), a 'verdade' artística não pode ser identificada à verdade científica ou à filosófica.

Sobre isso, Jorge Coli argumenta que

A arte tem assim uma função que poderíamos chamar de conhecimento, de 'aprendizagem'. Seu domínio é o do não-racional, do indizível, da sensibilidade: domínio sem fronteiras nítidas, muito diferente do mundo da ciência, da lógica, da teoria. Domínio fecundo, pois nosso contato com a arte nos transforma. Porque o objeto artístico traz em si, habilmente organizados, os meios de despertar em nós, em nossas emoções e razão, reações culturalmente ricas, que aguçam os instrumentos dos quais nos servimos para apreender o mundo que nos rodeia (COLI, 1995, p. 109).

Nesse domínio, sem fronteiras nítidas, o escritor tem a total liberdade para criar quaisquer eu líricos que sua imaginação lhe permitir, sendo que sua condição existencial não representa um limitador das suas produções. Logo uma escritora mulher tem a liberdade de inventar eulíricos homens, animais, crianças e assim por diante, até onde sua imaginação lhe levar.

Essa característica é possível pois a ficção, como aponta Llosa "não existe para investigar uma área determinada da experiência, mas para enriquecer de maneira imaginária a vida, a de todos, a vida que não pode ser desmembrada, desarticulada, reduzida a esquemas ou fórmulas, sem que desapareça" (LLOSA, 2009, p. 22).

Assim, sabendo que verdade científica e verdade literária estão em domínios diferentes, no encontro com textos literários o leitor não pode esperar um compromisso com evidências, métodos e teorias científicas. Pelo contrário, ao ler as obras infantis de Lewis Carrol, Odilon Moraes e Alexandre Rampazzo o leitor encontrará uma infância não condicionada às teorias psicológicas, e por vezes, até 
transgressora das ideias pelas quais se concebe cientificamente a infância. No entanto, ainda assim não deixa de ser uma representação da infância, porém, dessa vez, com uma proposta poética.

Para o filósofo, a criança enxerga grande, a criança enxerga belo, por isso, essa infância representada pelos poetas permanece como uma simpatia de abertura para a vida. Nesse sentido, em uma perspectiva fenomenológica, o devaneio voltado para a infância nos restitui à beleza das imagens primeiras (BACHELARD, 1988, p. 97).

Esse olhar poético para e sobre a infância tem muito a contribuir a sociedade como um todo, uma vez que permite acolher a infância como ela é, em todas as suas possíveis variações. Caso se restrinja a olhar para a infância apenas a partir de uma lente acadêmica corre-se o risco de repetir o mesmo padrão adultocêntrico produzido nos primórdios da literatura infantil, isto é, prever um tipo ideal de infância, no caso, aquele apresentado pelos tratados acadêmicos.

Nas palavras de Merleau-Ponty "não devemos considerar a criança do nosso ponto de vista, mas de um ponto de vista diferente do nosso. Precisamos tomar distância de nosso papel costumeiro. Precisamos despertar nossa própria espontaneidade" (MERLEAU-PONTY, 2006, p. 473).

Para Priore para se compreender a infância é necessário buscar "a história da criança simplesmente criança, as formas de sua existência cotidiana, as mutações de seus vínculos sociais e afetivos, a sua aprendizagem da vida" (PRIORE, 1999, p. 15). Esse movimento foi e ainda é realizado por muitos escritores que se dedicam ao universo infantil. Em vista disso, o livro infantil aparece como uma forma de experimentar a poética da infância e ir de encontro a um outro ponto de vista sobre a infância. Sobre esse olhar poético, que se aproxima de uma perspectiva fenomenológica, vale tecer algumas considerações.

\section{O livro infantil: uma poética da infância}

Em A educação do ser poético, Carlos Drummond de Andrade (1974) reflete sobre a poesia da infância. Para o poeta, a poética da criança encontra expressão cândida na meninice e está intimamente relacionada à necessidade de jogo, a ausência de conhecimento livresco e a despreocupação com os mandamentos práticos de viver. No entanto, este estado poético se esvai juntamente com a infância. Drummond (1974) então questiona "Por que motivo as crianças, de modo geral, são poetas e, com o tempo, deixam de sê-lo?" Para o poeta, essa perda de comunhão com a poesia está relacionada à escola que

Enche o menino de matemática, de geografia, de linguagem, sem via de regra, fazê-lo através da poesia da matemática, da geografia, da linguagem. A escola não repara em seu ser poético, não o atende em sua capacidade de viver poeticamente o conhecimento e o mundo. Sei que se consome poesia nas salas de aula, que se decoram versos e se estimulam pequenas declamadoras, mas será isso cultivar o núcleo poético da pessoa humana? (ANDRADE, 1974).

Possivelmente não, por isso, para Drummond é fundamental cuidar de uma extensão poética nas escolas, que daria às crianças condições de curtir a relação poética entre o ser e as coisas e, nas palavras do poeta, "valeria como corretivo prévio da aridez com que se costuma transcrever os destinos profissionais, murados na especialização, na ignorância do prazer estético, na tristeza de encarar a vida como dever pontilhado de tédio" (ANDRADE, 1974).

Assim como Drummond, Mario Vargas Llosa também vê na arte uma maneira de responder aos desencontros da era da fragmentação. Enquanto o poeta, atribui à poesia um papel fundamental, Llosa apresenta à literatura como um denominador comum entre as experiências humanas. Para o escritor 
Vivemos numa época de especialização do conhecimento, causada pelo prodigioso desenvolvimento da ciência e da técnica, e da sua fragmentação em inumeráveis afluentes e compartimentos estanques, tendência que não poderá senão se acentuar nos anos por vir. A especialização traz consigo, sem dúvida, muitos benefícios, porque permite aprofundar a exploração e a experimentação, e é o motor do progresso; mas determina também, como consequência negativa, a eliminação daqueles denominadores comuns da cultura graças aos quais os homens e as mulheres podem coexistir, comunicar-se e sentir-se de algum modo solidários. A especialização leva a incomunicabilidade social, à fragmentação do conjunto de seres humanos em estabelecimentos ou guetos culturais de técnicos especialistas... A ciência e a técnica não podem mais cumprir aquela função cultural integradora em nosso tempo, precisamente pela infinita riqueza de conhecimentos e da rapidez de sua evolução que levou à especialização e ao uso de vocabulários herméticos (LLOSA, 2009, p. 20).

Para Llosa (2009), ler bons romances é uma dessas formas, a partir da qual é possível aprender o que somos e como somos, em nossa integridade humana, com os nossos atos, nossos sonhos e os nossos fantasmas. Com a infância não é diferente, isto é, o estudo científico desta etapa do desenvolvimento é imprescindível, afinal é a partir dele que é possível controlar e prever fenômenos característicos dessa fase. No entanto, há algo na infância que escapa à ciência. Como afirma Drummond (1974), a infância é um modo de ser poético no mundo, sendo assim é preciso de poética para olhar para o poético da infância.

No entanto, assim como as escolas ensinam matemática sem a poesia da matemática, é possível que a mesma relação se estenda para o ensino universitário, isto é, o ensino da infância, sem a poética da infância. Dessa forma, o ensino da 'infância' corre o risco de perder o que há de mais singelo dessa etapa: o ser poético.

Enquanto Drummond sugere a poesia, Llosa o romance, a presente monografia sugere a Literatura Infantil como uma forma de responder a era da fragmentação, nesse caso, à fragmentação da infância.

\section{Considerações finais}

Quando um rico recurso é explorado apenas parcialmente, cabe ao pesquisador apontar outras formas de experienciá-lo. Assim o foi com o livro infantil e o presente trabalho. Ao propor uma nova maneira de olhar e vivenciar as obras infantis, a pesquisa em questão retoma a função social da arte, em especial, a função social de afirmar o lugar da infância em sociedade. Por esse motivo, o estudo em questão representa, sobretudo, um convite ao leitor para entrar nesse bosque chamado Literatura Infantil.

\section{Referências}

ANDRADE, Carlos Drummond de. A educação do ser poético. Jornal do Brasil, Rio de Janeiro, 20 de janeiro de 1974.

BACHELARD, Gaston. Os devaneios voltados para a infância. In: BACHELARD, Gaston. A poética do devaneio. São Paulo: Martins Fontes, 1988, p. 93-138.

BETTELHEIM, Bruno. A psicanálise dos contos de fadas. 6 ed. Rio de Janeiro: Paz e Terra, 1986. 
CADEMARTORI, Lígia. O que é literatura infantil. São Paulo: Editora Brasiliense, 1986. (Coleção Primeiros passos, 163).

CANDIDO, Antônio. A literatura e a formação do homem. Campinas: Unicamp, 2012.

COLI, Jorge. O que é arte. 9 ed. São Paulo: Brasiliense, 1995. (Coleção Primeiros Passos).

COELHO, Nelly Novaes. A literatura infantil! abertura para a formação de uma nova mentalidade. In: COELHO, Nelly Novaes. Literatura infantil: teoria-análise-didática. São Paulo: Moderna, 2000. p. 14-45.

DEL PRIORE, Mary (Org.). História das crianças no Brasil. São Paulo: Contexto, 1999.

ECO, Umberto. Seis passeios pelos bosques da ficção. 14 ed. São Paulo: Companhia das Letras, 2019.

FREITAS, Marcos Cezar. Por uma sociologia histórica da infância no Brasil. In. FREITAS, M. C. (Org.). História social da infância no Brasil. 9. ed. São Paulo: Cortez, 2016.

GIL, Antonio Carlos. Métodos e técnicas de pesquisa social. 6. ed. São Paulo: Atlas, 2008.

HILLESHEIM, Betina et al. Leitura: entre leitor e texto. Fractal, Rev. Psicol., Rio de Janeiro, v. 23, n. 2, p. 305-315, 2011. Disponível em http://www.scielo.br/scielo.php?script=sci_arttext\&pid=S198402922011000200006\&lng=en\&nrm=iso. Acesso em: 06 nov. 2019.

VARGAS LLOSA, Mario. É possível pensar o mundo moderno sem o romance? In: MORETTI, F. (Org.). A cultura do romance. São Paulo: Cosac Naify, 2009, p. 18-32.

LEITE, Dante Moreira. Psicologia e literatura. São Paulo: Editora Unesp, 2002.

MERLEAU-PONTY, Maurice. Método em psicologia da criança. In: Psicologia e pedagogia da criança. São Paulo: Martins Fontes, 2006, p. 463-534.

MORAES, Odilon. Olavo. São Paulo: Jujuba, 2018.

PALO, Maria José; OLIVEIRA, Maria Rosa D. Literatura infantil: voz de criança. São Paulo: Ática, 1998.

PROUST, Marcel. O tempo redescoberto. São Paulo: Globo, 2013.

RAMPAZZO, Alexandre. Pinóquio: o livro das pequenas verdades. São Paulo: Boitatá, 2019.

RICOEUR, Paul. A vida: uma narrativa em busca do narrador. In: RICOEUR, Paul. Escritos e conferências 1: em torno da psicanálise. São Paulo: Edições Loyola, 2010. p. 197-212.

ZILBERMAN, Regina. A literatura infantil na escola. 11. ed. São Paulo: Global, 2003.

WALTY, Ivete Lara Camargos. Língua Portuguesa: os sentidos da leitura. Presença Pedagógica, Caiçara, n. 4, jul./ago., p. 22-37, 1995. 
LITERATURA INFANTIL: UM ENCONTRO COM A INFÂNCIA DO MUNDO

WAPICHANA, Cristino. A boca da noite. Rio de Janeiro: Zit, 2016.

\section{Sobre a autora}

Juliana Bruna de Freitas. Bacharel e licenciada em Psicologia pela Pontifícia Universidade Católica de Minas Gerais - PUC MG.

E-mail: julianafreitas0001@ @otmail.com. 